\title{
TRES EPISODIOS DE ASENTAMIENTO Y UN DIARIO DE OBRAS EN PASO DEL NorTE EN EL SIGLO XVIII
}

ALEJANDRO GONZÁLEZ MILEA ${ }^{1}$

\section{RESUMEN}

」t as investigaciones sobre el poblamiento de Nuevo México, en el siglo xvII, han venido refiriéndose a la dispersión de los asencompactación o concentración de los habitantes. Si bien solamente unas veces lograron construirse los recintos fortificados denominados "plazas", sobre todo con motivo de nuevos establecimientos, en la jurisdicción Paso del Norte la idea se enfrentó con la oposición de los vecinos y se ha afirmado que no hay evidencia de que algo se hubiera practicado en tal sentido. Sin embargo, el hallazgo de un diario que elaboró el capitán Diego de Borica en 1782, para conseguir "la reunión de indios y vecindario", sugiere matizar el anterior argumento, informar sobre la vida del personaje y, al mismo tiempo, revisar algunos tópicos de la historiografía del poblamiento en la frontera norte.

Palabras clave: asentamiento, plazas, poblamiento.

\section{INTRODUCCIÓN}

Es interesante revisar las estrategias de poblamiento que se impulsaron, durante el siglo xviI, en la jurisdicción Paso del Norte. Entre otras razones, porque se aprecia la continuidad entre las ideas de

1 Docente investigador de la Universidad Autónoma de Ciudad Juárez, México. Correo electrónico: alejandromilea@ prodigy.net.mx 
los gobernadores y los criterios unificadores de la Comandancia General de Provincias Internas; pero también porque existen referencias a decisiones de establecimiento y construcción que no han sido estudiadas. No se trata solamente de algunas instrucciones de los conocidos ingenieros militares de élite que vinieron de España (Arnal, 2017), y otros delineadores y demarcadores de tierra, sino también de acciones más prácticas y que se resolvían sobre la marcha. Estudiar las operaciones de establecimiento en Paso del Norte, desde los criterios que arroja la evidencia documental de índole técnica, permite profundizar en las motivaciones que obligaban a tomar diversas decisiones de arreglo del espacio.

Hay que recordar que, aunque existen pocos datos sobre el plan de establecimiento de la misión franciscana en Paso del Norte, queda claro el predominio que ejerció —desde mediados del siglo xVI - el modelo de riego a través de una o varias acequias (González, 2012, pp. 46-47). José Fayni, refiriéndose a esta oscura etapa, ya se había preguntado por qué los misioneros habían favorecido o permitido establecer las casas de forma dispersa. ${ }^{2}$ La rebelión de Nuevo México y la llegada de refugiados ocasionaron varios reacomodos, durante el tránsito al siglo xvIII, pues se ubicaron cuatro "campos reales" que en adelante fueron dando lugar a los establecimientos de misioneros (González, 2012, pp. 48-49). Bajo la vigilancia del gobernador Otermín intentó definirse un cuadrilátero para la sede de poderes (Santiago, 2013, p. 59), aunque sin referencias claras a cómo pudo implementarse. De tal modo que, para inicios del siglo xvIII, se había ido configurando un "sistema militar" sólido, que dio coherencia a la defensa de Sonora, Nueva Vizcaya y Nuevo México (Santiago, 2013, p. 50), y el patrón de asentamiento disperso permitiría que a lo largo del siglo xviI indios y pobladores hispanos convivieran de cerca (González, 2012, p. 50). Aun así suele afirmarse que no existía "ningún diseño de calles u orden espacial" en la época (Santiago, 2013, p. 50); sin embargo, también se afirma que -siguiendo a Michael C. Meyer (1984) - se construyó un complejo sistema de irrigación (Santia-

2 Nuevo método de gobierno espiritual y temporal, México, 1773, AGn, Provincias Internas, Vol. 43, Exp. 1 (1773). 
go, 2013, p. 59). Las referencias permiten plantear una pregunta: ¿es posible identificar las intenciones ordenadoras del espacio y establecer alguna clasificación? En la época, por ejemplo, es claro que la distribución que respondía a los requerimientos de riego por acequias, se valoró de forma negativa y también positiva, pero la idea de que la compactación y los trazos reticulares eran beneficiosos igualmente veía en la dispersión un inconveniente. ¿Qué debates y respuestas se dieron en torno a estos problemas?

Un estudio de las entradas españolas, durante el siglo XVII, arrojaría muchas razones que provocaron la dispersión del asentamiento. Los primeros establecimientos, por ejemplo, buscaron sitios en el interior o centro de los pueblos indios ya conformados, pues en un ejemplo se dijo: "Partieron los indios habitadores del Pueblo de muy buena voluntad sus viviendas con los nuestros españoles" (Villagutierre, 1601). También hay que considerar que los franciscanos de Nuevo México no buscaron fortificar sus pueblos misión, al contrario de lo que sucedió - ya en el siglo xvII- en Texas (Ramiro, 2013, pp. 89-93). Algunos estudiosos atribuyeron la dispersión a la particular conformación del medio geográfico, mientras que otros buscaron las razones en las dinámicas sociales. Para el primer caso, se refirieron a que los asentamientos buscaron la proximidad de los ríos, pero estableciéndose en las pocas mesetas que eran susceptibles de cultivarse, cortas en superficie. En el segundo, el énfasis estuvo puesto en la ocupación de familias españolas que conformaron ranchos (Kelley, 1955, pp. 387-394).

En un primer apartado se revisan las operaciones de asentamiento de indios sumas en San Lorenzo, llevadas a cabo entre 1730 y 1760, y también las Providencias para reparto de tierra a los indios, dictadas en 1751 por Tomás Vélez Cachupín para Paso del Norte, todo esto para discutir los orígenes y las razones de los asentamientos dispersos. En un segundo apartado, a través de revisar el proyecto de poblamiento de San Fernando de las Amarillas del Carrizal de 1758, se discuten las limitaciones de los planes para construir poblaciones compactas. Se analizan enseguida los criterios para juzgar la dispersión y buscar la compactación que emanaron de los gobiernos y la Comandancia General de Provin- 
cias Internas. Y en el cuarto apartado, se ofrece una revisión del diario, inédito, que elaboró Diego de Borica, antecedido por un análisis de su trayectoria para reflexionar sobre sus dotes prácticas de ordenador del territorio.

\section{EL ASIENTO DE SUMAS EN SAN LORENZO}

La idea de asentar sumas en San Lorenzo, se remonta a una instrucción dada, en 1712, por Juan Ignacio Flores Mogollón —gobernador de Nuevo México- al capitán del presidio de Paso del Norte, Antonio Valverde y Cosío, quien debería "reducir a pueblo" a los indios cristianos y gentiles, y elegir el mejor sitio para los asentamientos. $^{3}$ Si bien, el brigadier Pedro de Rivera (1945) comentó que San Lorenzo era "pequeña población de habitadores, como los del Paso”, en la década de 1720 también supervisó la entrega de tierras a los sumas; escribió en su diario: "les amonesté se poblasen, para que viviesen en vida política, y se les daría bastimentos ínterin que los cogiesen en la tierra que se les señalase para sus siembras, y aperos para su cultivo" (De Rivera, 1945, pp. 74-75). Si bien, las operaciones también se refirieron a sitios como Palo Clavado, en las inmediaciones de la hoy Ojinaga, al paraje de Guadalupe y a la hacienda de Carrizal, el sitio de San Lorenzo ocupó la mayor atención. También en 1731, el obispo de Durango, Benito Crespo y Monroy, comentó en su informe de visita que había encontrado en Paso del Norte muchos sumas, gentiles y otros indios con carácter de apóstatas, y los había convencido de que lo siguieran, porque habían pedido asentarse en un pueblo. El obispo pasaría este trámite al capitán, porque consideró que no era conveniente ponerles un ministro, hasta "asegurarlos bien"; y luego se verificó que estaban "muy firmes y poblados con el número de trescientos" . Pero otros informes de una década después sugieren la inestabilidad de este asentamiento, pues mientras una carta de fray Miguel de Menchero afirmaba que los sumas se habían

3 Mandamiento de don Juan Ignacio Flores Mogollón para reducción de la nación Suma, Santa Fe, 1712, sAnM, Roll 6.

4 Informe de la visita del Señor Obispo de Durango, 1731, AGi, Guadalajara 400. 
establecido efectivamente en San Lorenzo, y estaban siendo ya instruidos, en otra misiva de fray Manuel de San Juan Nepomuceno y Trigo, se informaba que ya no había indios en dicho punto. ${ }^{5}$

No sabemos si con motivo del anterior plan, o mediante otro nuevo, pero solamente a partir de 1762, durante el gobierno de Tomás Vélez Cachupín, dieron inicio las operaciones de medición, quedando a cargo de vigilarlas el justicia mayor, Joseph de Horcasitas, y con la presencia del ministro misionero fray Joseph Páez. Una primera consideración fue reunir a todos los sumas que se hallaban dispersos en Senecú, Isleta y Socorro, ahora en San Lorenzo, dado que existía tierra suficiente para la labor. Se debería ubicarlos en un cuadro de 1250 varas, pero durante la revisión de la medida tuvieron que ampliarse hacia uno y otro lado tramos de hasta 100 varas, porque la acequia (probablemente la que años después se llamó del Chamizal) no alcanzaba a "derramarse sobre las tierras". Incluso, el comisionado de las medidas, después de otra revisión, mandó abrir dos nuevas acequias estando presentes los vecinos de San Lorenzo para que no hubiera conflictos. La medida no debió satisfacer a los sumas, pues en el año de 1765 se quejaron de la injusta distribución de tierras que habían recibido. ${ }^{6}$ El capitán Pedro de la Fuente revisó la operación realizada y, a pesar de haber sido hecha para asegurar el riego, su criterio parecía referirse a otra cosa, a decir de las primeras medidas llevadas a cabo: "consta en estas diligencias [que] más de esto procedió en dichas medidas sin conocimiento del hecho, pues ni fue perfecto el triángulo el que formó, ni cuadro como debía ser". Los sitios donde parece que los sumas se aglomeraron fueron el Álamo Gacho, hacia el sur, y el lindero con Senecú, y se refieren a las seis labores de panllevar que se les repartió. ${ }^{7}$

Pero más allá del riego de la tierra, otro aspecto que demuestra la fragilidad del asentamiento suma frente a los vecinos, fue el modo de aprovechar los materiales de los terrenos. El mismo

5 Declaration of Fray Miguel de Menchero, Santa Bárbara, 1744 (Hackett, 1926, p. 406); y Letter of Father Trigo, Istacalco, 1754 (Hackett, 1926, pp. 459-462).

6 Demarcación y medidas de tierra a los indios sumas del Pueblo del Real de la Jurisdicción del Paso, 1765, sanm, Roll 6.

7 Ibidem. 
año sucedió una controversia entre ocupantes de Paso del Norte y San Lorenzo por la extracción de materiales leñosos, como lata, jara, cachanilla, madera de tornillo y leña. Los sumas -representados por el infiel-cacique Antonio Pastor, y el mandón gobernador Agustín - argumentaban que los vecinos del Paso debían procurar extraer sus materiales de sitios como Salineta, pues contaban con carretas y bueyes para el transporte. En cambio, los sumas tenían que procurárselos cerca, porque "no tienen carretas ni modo de traerlo sino a sus lomos". La anterior medida en cuadro no debió tener ningún efecto, pues el lindero que aquí se mencionó era una acequia. El colmo fue el descubrimiento de un negocio ilícito, llevado por el teniente de los cuatro pueblos, que permitía a gente de Paso del Norte entrar por carretillas de material a todos los terrenos, a cambio de una bonificación. ${ }^{8}$

Estos y otros factores debieron constituir razones de peso para que los sumas se alejaran. Pero queda claro que si las labores de panllevar se dieron a los indios, adecuadas a la pendiente de las acequias, otro problema distinto -y quizá aplazado de forma indefinida - fue el cuadro de 1250 leguas, impracticable por el curso caprichoso de pendientes de riego y tierras altas y bajas.

Por lo anterior, no deja de asombrar el contenido técnico de las instrucciones para establecer la villa del Pitic —emitidas cerca de veinte años después-, sobre todo respecto a las tierras para los indios. En su numeral 19 indicaban:

[...] Siendo el beneficio del riego el principal medio de fertilizar las tierras y el más conducente al fomento de la población pondrá particular cuidado el comisionado en distribuir las aguas de modo que todo el terreno que sea regable pueda participar de ellas especialmente en los tiempos y estación de primavera y verano, en que son más necesarias a las sementeras, para asegurar las cosechas, a cuyo fin valiéndose de peritos o inteligentes dividirá el terreno en partidos o heredamientos señalando a cada uno un arbollón o acequia, que saldrá de la madre o principal con la cantidad de agua que se regule

8 Autos seguidos de competencia entre los vecinos del Pueblo del Paso y los de San Lorenzo, Paso del Norte, 1765, SAnM, Roll 6. 
Tres episodios de asentamiento y un diario de obras en Paso del Norte...

suficiente para su regadío en los enunciados tiempos, y en los demás del año que la necesitaren [... $]^{9}$

\section{LA PROVIDENCIA DE TOMÁS VÉLEZ CACHUPÍN}

En su exploración de 1720, Pedro de Rivera caracterizó el área central de Paso del Norte como un presidio "con una moderada población de españoles, mestizos y mulatos", y un pueblo "separado en dos cuarteles" habitado por indios mansos y piros (De Rivera, 1945, p. 67). En el año de 1751 se reconfiguraba la posesión de tierras con clara orden de que no se molestara a los indios. El gobernador, Tomás Vélez —conocido por ser "protector de indios"- (Ebright, 2014, pp. 196-199), emprendió así un reparto para mansos, piros, tiguas y otros; las instrucciones parecen dejar en claro que los indios tendrían que cultivar sus tierras, sin venderlas ni prestarlas, y con una aclaración dudosa acerca de si podían construir sus casas y solares en estas áreas. El párrafo en cuestión lo transcribió Armando B. Chávez (1970) del siguiente modo: “...que en dichas tierras habían de sembrar todo género de semillas que quisieran, sin huertas, sin casas ni solares y no en otra parte..." (p. 153); mientras que Wilbert H. Timmons (1990) lo puso en los siguientes términos: "They were authorized to plan whatever seeds they wished, and their lands were to remain free of orchards, houses, and structures" (pp. 36-37). Agregó Timmons (1990) que se trataba de cuatro grupos de indios, que recibirían una legua a cada lado de la iglesia; la medida debió significar un cambio drástico, pues ahora en lugar de tierra comunal administrada por los religiosos, se impulsaba a los indios a ser propietarios, pues se mencionaron "títulos" (p. 37).

El expediente que contiene la Providencia, dictada por Tomás Vélez, se basaba en las diligencias de visita que, sobre todo, se habían propuesto hacer un reconocimiento de tierras, debido

9 Instrucciones para establecimiento del Pitic, Chihuahua, 1800, SANM, Roll 6. La fundación se hizo hacia 1783, y esta es una copia posterior que, como han señalado algunos estudiosos, sirvió para orientar muchos otros establecimientos en el septentrión novohispano. Es importante señalar que su concepción se atribuye al ingeniero Manuel Agustín Mascaró. 
al desorden e irregularidad de su uso, disfrute y posesión, que durante un tiempo habían observado los habitantes de Paso del Norte. Se instruía así al capitán Manuel Vitores Rubín de Celis, del presidio del Paso, para que enterara a los naturales de las tierras útiles que se ubicaban hacia el sur, para repartirlas y amojonarlas, con la aclaración de que no se les molestara "como no menos que se les inquiete en el uso y posesión de los solares para casas y huertas que dichos naturales tengan fabricadas y plantadas en cualquier parte o lugar de esta dicha poblazón”. ${ }^{10}$

Lo mismo se indicó para la parte norte, en los sitios "que llaman de los mansos" —en este momento ya desocupados-, y que serían repartidos a vecinos españoles. Entre las medidas que había que tomar también estuvo el cuidado de todas las acequias, que deberían mantenerse limpias y en corriente. Los indios, para la parte del sur, deberían presentarse a manifestar las tierras que tuvieran o necesitasen, "así para sus siembras, como para solares, casas y huertas", sobre lo cual se haría el amojonamiento y elaboración de testimonios que sirvieran de títulos. ${ }^{11}$ Las operaciones de medición arrojan otras cuestiones de interés. El lindero del norte sería un arroyo donde se ubicaba el desagüe de la acequia de Valencia (después probablemente llamada Chamizal) y a través de su curso, hacia el oriente, se plantarían álamos para su conservación, hasta el lindero con Senecú, y otras áreas de ocupación se dieron hacia el sur y el poniente, en las Lomas, es decir, las partes más altas rumbo a las estribaciones de la sierra. ${ }^{12}$

La referencia a que se podía o no construir casa en realidad fue ambigua, pues no son equivalentes las denominaciones de solar, huerta y tierra de labor (también llamada suerte), aunque en la práctica las huertas terminaran siendo, en algunos casos, lugares de residencia. Pero también sobresale que existía mucha informalidad en la posesión de terrenos. Puede afirmarse así que

10 Providencia del Señor Gobernador don Thomas Vélez Cachupín sobre solares, casas y tierras de laborío, Paso del Norte, 1751, AHCJ, FC, Caja 13, Exp. 1.

11 Ibidem.

12 Ibidem. 
Tres episodios de asentamiento y un diario de obras en Paso del Norte...

la dispersión respondió tanto a esta condición como a los requerimientos particulares del riego. ${ }^{13}$

\section{LA NUEVA POBLACIÓN DE SAN FERNANDO DE LAS AMARILLAS DEL CARRIZAL}

Los eventos de expulsión de españoles en Nuevo México, hacia finales del siglo xvII, provocaron replanteamientos en las estrategias de poblamiento. Parece que solo entonces comenzó a pensarse que el aislamiento de los grupos de asentamiento — sumadas las largas distancias que los separaban - había constituido la razón principal de la pérdida de esa provincia (Simmons, 1976, p. 83). Las respuestas no se hicieron esperar, y aunque los establecimientos de presidios se habían venido haciendo - hasta inicios del siglo XVIII- como iniciativas impulsadas con sus peculiaridades por cada gobernador, sería en los territorios más septentrionales desde finales del siglo xvII donde José Francisco Marín —visitador de las guarniciones de Nueva Vizcaya- recomendó el movimiento de sitio de las compañías, con la finalidad de promover la consolidación de comunidades civiles. Moorhead (1975) sugiere que es aquí de donde pudo provenir el conocido proyecto de Teodoro de Croix, para colonizar con civiles de décadas después. Aunque, con anterioridad, el caso de San Fernando de las Amarillas del Carrizal ya mostraba algunos elementos de esta concepción (Moorhead, 1975, pp. 222-227; Vázquez, 2013, pp. 138-143).

La idea del establecimiento de Carrizal, se originó en una junta de guerra celebrada en la ciudad de Chihuahua, en 1751, donde, entre otras cosas, se habló de la necesidad de poblar el puesto de Robledo, río arriba de Paso del Norte, y ubicar otro punto más hacia el sur. El lugar elegido para este último fue la hacienda de Nuestra Señora de los Dolores del Carrizal, y la idea era que debería poblarse con cincuenta familias y a cuenta de la Real Hacienda. Pero en consulta con el capitán del presidio de Paso del Norte, Manuel Vitores Rubín de Celis, se consideró que podía hacerse

13 En todas estas operaciones el demarcador de tierras fue Bernardo de Miera y Pacheco, y es claro que se trata de un episodio de poblamiento. 
de otra forma, y ejecutarlo a sus expensas. Entonces se comentó también la necesidad de seguir un método “...o planta que sea con modo a su lucimiento y a la defensa del vecindario”. "El dibujo parece haberlo elaborado Manuel de la Torre -teniente de capitán del presidio de Nuestra Señora de las Caldas de Guajoquilla-, porque durante las correspondencias para definir al encargado del establecimiento señaló:

... me ha parecido conveniente remitirle el diseño, o planta en que parece regular, se establezca dicha poblazón para en sus principios, y en los progresos pueda adelantarse, se logre la comodidad y hermosura que se hace apreciable en tales obras. Y como la buena o mala dirección en el plantel de un lugar, ni quita ni añade costo, por esto y por lo que pueda importar, no he querido omitir dicha remisión. ${ }^{15}$

14 Diligencia practicada para el pueblo del paraje del Carrizal por el sargento mayor don Manuel Antonio San Juan, Paso del Norte, 1758, AHCJ, FC, Caja 1, Exp. 2.

15 Ibidem 
Figura 1. Proyecto de establecimiento de colonos en San Fernando de las Amarillas del Carrizal, 1782

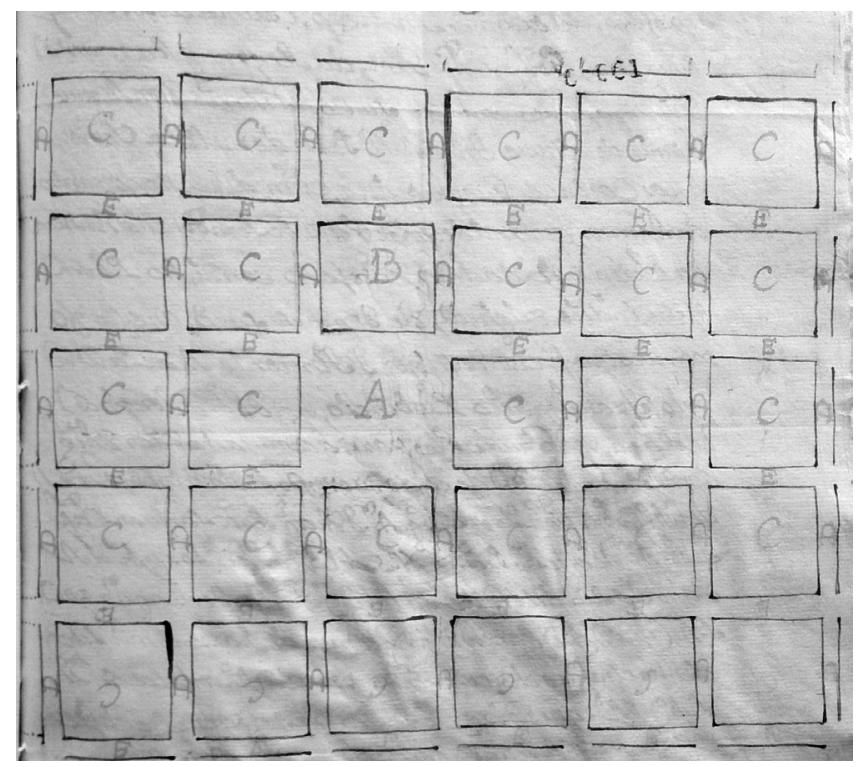

Fuente: Índice o descripción plana del pueblo que se pretende hacer en el paraje llamado del Carrizal, 1782. AHCJ, FC, Caja 1, Exp. 2. Por el contenido del expediente se deduce que, primero, habría que formar el recinto cerrado que se denominaba como "plaza", y ya después - si las condiciones lo permitían- se abrirían las calles hacia los extremos.

Solamente hasta 1758 lograron reunirse las familias -provenientes de Paso del Norte- para poblar el Carrizal. Se contaron, para empezar, cincuenta y dos de ellas en febrero, y se arribó al sitio ya para el mes de noviembre de ese año. Al siguiente día del acto de establecimiento, se procedió a ocupar las ruinas de las viejas casas y jacales de la hacienda, mientras se comenzaba a construir las propias; las acequias existentes estaban destruidas y anegadas, por lo que se emprendieron también labores de reparación y limpieza. Se asignó, por último, una escolta de veinte soldados de Paso del Norte, y se formó una milicia de tres escuadras. ${ }^{16}$

16 Ibidem. 
Una idea de este tipo de establecimientos era que los vecinos formaran milicias -ejércitos informales constituidos por vecinos-, para liberar la carga de los soldados de presidios. Para el año de 1763, con motivo de que se anunció que se retiraría del Carrizal la escolta de soldados los pobladores protestaron. Un asunto que entonces emergió fue que inicialmente los pobladores no habían construido de acuerdo con el plano enviado, y más bien lo habían hecho de forma dispersa, junto a las acequias y sus campos de cultivo. ${ }^{17}$ El argumento de los pobladores para haberse asentado de este modo fue la gran dificultad para atraerse materiales de construcción, primeramente la madera, y la urgencia que habían tenido de cultivar la tierra y reparar las acequias. En un sentido parecido preguntaban, en caso de que se les obligara a reunirse en la plaza, qué sucedería con todo lo que habían invertido hasta ahora en sus actuales casas. ${ }^{18}$

\section{LA DISPERSIÓN Y LA REUNIÓN EN EL ASENTAMIENTO}

En el año de 1772 el gobernador de Nuevo México -Pedro Fermín de Mendinueta-, ya cerca del final de su mandato, elaboró dos informes sobre la tendencia al asentamiento disperso y delineó recomendaciones sobre cómo proceder. El énfasis lo puso en la necesidad de que los pueblos de españoles tomaran el modelo de asentamiento de los indios, para defenderse de los ataques en las planicies (Thomas, 1931, pp. 21-22). El informe asumía, primero, que una de las causas de la indefensión del territorio era la dispersión de los asentamientos españoles; en segundo lugar, las medidas propuestas eran claras: había que obligarlos a unirse y formar pueblos en plazas o calles, de manera que pocos hombres pudieran defenderse a sí mismos. Esto requería el ejercicio de la autoridad (Thomas, 1931, p. 29). Pero el elogio de las tierras cultivadas en grandes extensiones también supone un criterio diferente, pues con motivo de que Antonio María Sánchez de Daroca

17 Testimonio de las diligencias practicadas en virtud del escrito presentado por los vecinos de la nueva población de San Fernando de las Amarillas, Paso del Norte, 1763, AHCJ, FC, Caja 4, Exp. 2.

18 Ibidem. 
envió su informe sobre la visita a Paso del Norte, no pudo dejar de comentar sobre el asentamiento:

... porque están en tal disposición que cada vecino e indio viven en medio de sus bienes de modo que no hay dos casas juntas, y están más o menos apareadas, según es mayor o menor la posesión; hay de aquí a Casa de los Tiburcios siete leguas y todo está poblado como la Huerta de Murcia (Hendricks, \& Timmons, 1998, pp.13-15). ${ }^{19}$

Es importante saber que entre varios encargos que tuvo este visitador estuvo el de organizar las milicias (Timmons, 1990, pp. 46-47).

19 Informe de visita al Paso, Paso del Norte, 1773, Agn, Provincias Internas, Vol. 102, Exp. 1. 
Figura 2. Dos patrones comunes de establecimiento en Nuevo México
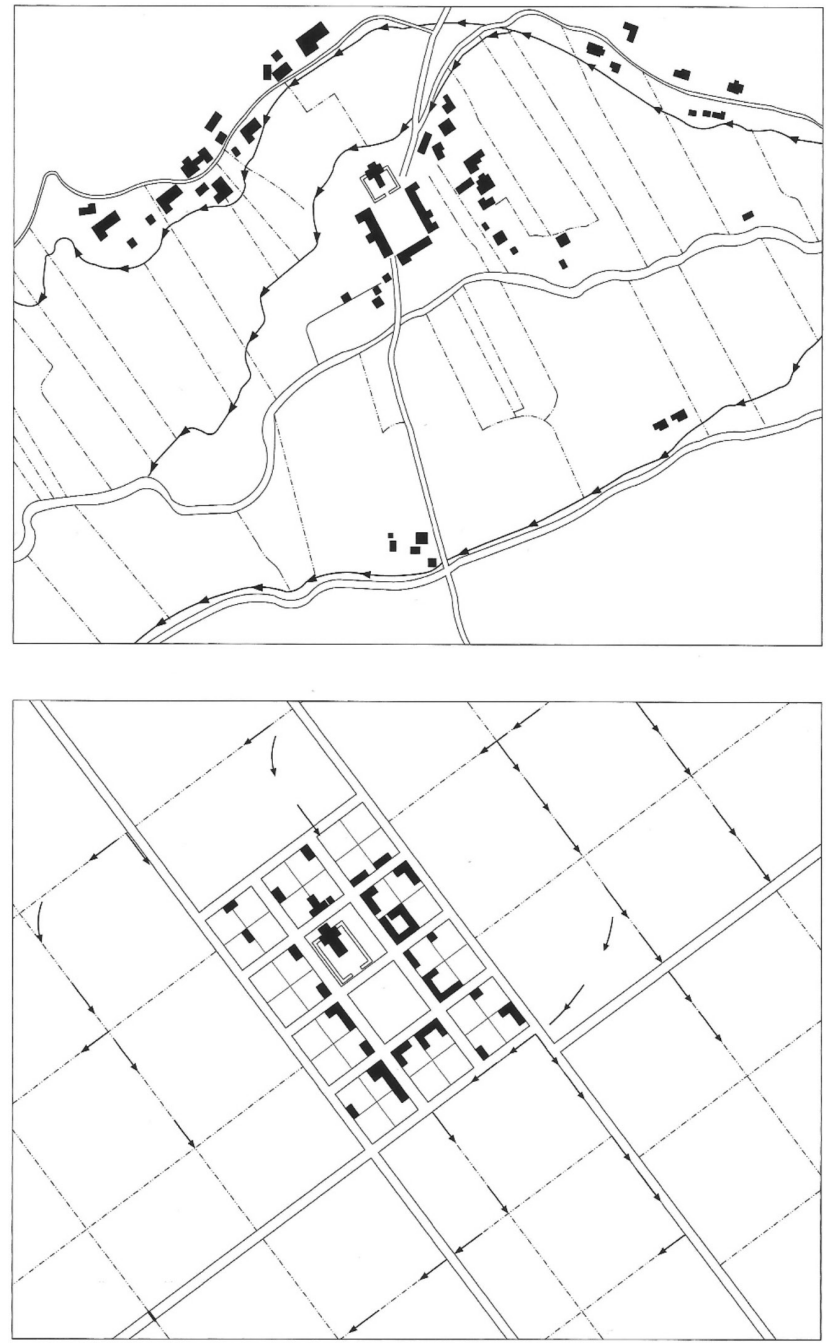

Fuente: tomado de Wilson (2011). Es evidente que la concreción de uno u otro modelo dependió en parte del sitio elegido para el establecimiento, asunto que también constituyó un criterio de índole técnico, aunque también pudo estar la posibilidad de ajustarse a una oportunidad.

Aunque Teodoro de Croix recibiría el mando de la Comandancia General en 1776, y arribaría a la frontera hasta octubre de 1777, ya desde antes opinaba sobre las ideas de De Mendinueta. 
Sobre la urgencia de obligar a los habitantes a reunirse señaló que probablemente muchos ocupantes fueran solamente "invasores", y de esta forma "el daño sería menor" si se les obligaba a dejar sus tierras y convertirse en nuevos pobladores (Timmons, 1990, pp. 3133). Los informes del secretario de la comandancia - Antonio de Bonilla- son ilustradores de las implicaciones de lo anterior, pues no solo se trataba de mover a la gente que ya estaba asentada, y obligarla a poblar en un nuevo sitio, sino también a que contribuyera con armas y animales para la defensa -aspecto práctico de la formación de las mencionadas milicias (Thomas, 1931, pp. 185-189).

Las ideas iniciales de De Croix parecen haber sido el incremento de las tropas presidiales, la creación de milicias provinciales y compañías volantes. Pero la entrada de España en la guerra con Inglaterra había reducido mucho los gastos, y el plan debió limitarse únicamente a la parte defensiva (Timmons, 1990, pp. 48-49). Los resultados debieron fructificar, pues para 1779 se habían formado seis cuerpos de milicia en Nueva Vizcaya y uno en Coahuila, comprendiendo en total 1852 españoles y 1331 indios auxiliares (De Palo 1973, pp. 225 y ss.). También se buscó reforzar la ubicación estratégica de Paso del Norte, a través de promover el establecimiento de dos presidios -en Robledo y Carrizal- y la conformación de una milicia en el lugar (Thomas, 1941, pp. 38-39, 53). ${ }^{20}$

Los posibles establecimientos de Robledo y Carrizal, se apoyaban en la numerosa población que había en Paso del Norte y pueblos adyacentes. Con la concurrencia de mucha gente, que se había originado con la llegada de refugiados por la pérdida de Nuevo México, faltaba tierra para cultivar y dichos establecimientos podrían aliviar la presión de ocupantes o la aplicación del plan de reunión. ${ }^{21}$

20 Este plan para Carrizal es posterior al nuevo establecimiento revisado líneas atrás. Por otra parte, tanto David Weber (2000, p. 305) como Luis Arnal (1998, p. 157) recalcan que, además de los presidios, existieron otras estructuras defensivas, como los bastiones, los baluartes y los torreones, que han sido menos estudiados.

21 Representación de Hermenegildo Montoya en nombre de los vecinos del Paso del Río del Norte, Paso del Norte, 1766, Agn, Provincias Internas, Vol. 102, Exp. 1; e Informe de Tomás Vélez Cachupín a Teodoro de Croix, Santa Fe, 1767, idem. 
Más adelante, se sumó un consejo de guerra que se celebró en la ciudad de Chihuahua en 1778, y también el plan que ya entonces delineaba Juan Bautista de Anza, sucesor de De Mendinueta, en el gobierno de Nuevo México. Este plan, pensado para iniciarse en Paso del Norte, debería asegurar cierto estado de paz (Herrera, 2004, p. 522). El consejo daba al gobernador suficientes atribuciones para comenzar una reforma profunda en la organización de milicias y ordenamiento físico de los asentamientos (Herrera, 2004, p. 503). De este modo, Juan Bautista de Anza conferenció con grupos de pobladores de Nuevo México, explicándoles los requerimientos para la defensa. En Santa Fe, Albuquerque y Taos tuvo éxito y la población se reunió en plazas, al menos cincuenta familias en cada una. Estos resultados animaron a que el experimento se aplicara en Paso del Norte (Timmons, 1990, pp. 49-50), pero la sola propuesta ocasionó mucho descontento entre los vecinos, quienes arguyeron que el alejamiento de sus tierras y huertas provocaría una depresión sin precedentes en la zona, y esto, incluso -enfatizaron-, podría comprometer en el futuro el pago de diezmos y alcabalas (Timmons, 1990, pp. 50-51).

El decreto que emitió De Anza llama la atención, porque, además de implicar la reunión en plazas, se refirió con más énfasis a que los habitantes deberían construir bardas alrededor de sus tierras y huertos, para reducir los estragos de los robos de los indios (Herrera, 2004, p. 512). Esto sugería una solución más realista, aunque implicaba más gastos para los vecinos. El argumento de estos, en contraste, deja entender varias cosas del arreglo espacial:

... pues sus casas se hallan situadas unas con otras, en distancia de un tiro de escopeta, las más a tiro de pistola, y una o dos que son más distantes se hallan en la de 150 varas. La última de esta población, que es la del capitán Don Francisco Elías en distancia de 650 varas al poblado que llaman del Real, y a todos los demás vientos de su circunferencia se registran poblaciones muy inmediatas que aseguran su resguardo. ${ }^{22}$

22 Protesta de los vecinos de Paso del Norte, Paso del Norte, 1780, SAnM, MF454, Roll 11. 
Esta distribución en su juicio ayudaba a la defensa, porque los pobladores se hallaban cerca de sus huertas o labores de cultivo. Se sumaba la consideración de que Tomás Vélez Cachupín había dado tierras para que se fuera ocupando el espacio entre Paso del Norte y San Lorenzo. ${ }^{23}$

Ahora bien, en la historiografía reciente solamente los estudios de Carlos Herrera (2004, pp. 515-517) y Wilbert Timmons (1990, pp. 50-51) pusieron énfasis en esta operación en específico. Sobre todo el segundo, quien afirmó que no hay referencias que permitan asegurar que algo concreto se hiciera.

\section{DIEGO DE BORICA Y SU DIARIO PARA REUNIÓN DE INDIOS Y VECINDARIO}

En este apretado contexto apareció el teniente Diego de Borica, encargado de varias operaciones de la Comandancia General. ${ }^{24}$ El año de 1795, con motivo de la búsqueda de un nuevo puesto burocrático, presentó su listado de servicio teniendo entonces cincuenta y tres años cumplidos. Mencionó que primero había servido de cadete de infantería, luego como teniente de infantería y caballería, algunos pocos años de capitán, y de ayudante inspector con la antigüedad de teniente coronel. Sobre todo en este último cargo había ejecutado mariscadas contra comanches y apaches, y había llegado a tener bajo sus órdenes hasta doscientos cincuenta hombres. Desde 1779 había quedado encargado de la Subinspección de Presidios de Nueva Vizcaya, elaborado veintitrés revistas de inspección y, sobre todo, "había arreglado las milicias de Paso del Norte", con su reglamento, y "dispuso las obras de reunión de tan dilatada población para libertar al vecindario de los insultos de los enemigos", cooperando asimismo en el establecimiento de otras poblaciones militares. En fin, también había tenido a su cargo la segunda y cuarta divisiones de la frontera de Nueva Vizcaya, y luego

23 Ibidem.

24 Existen algunas referencias a este personaje en su paso por Nueva Vizcaya (Ortelli, 2007, pp. 70-71; Torales, 2001, pp. 247-249; Urquidi, 1992, p. 671), sin considerar su papel en California; pero poco se sabía sobre su desempeño en varias comisiones. 
el de toda la Provincia. Durante los años de 1786, 1790 y 1791 se le encargó la visita de los tarahumaras, tepehuanes y de otras poblaciones de españoles en Nueva Vizcaya. ${ }^{25}$ Si bien, para esta fecha tan tardía De Borica ya había sido asignado como gobernador a la Alta California, también había buscado que se le diera la Intendencia de Zacatecas, y se le había mencionado para una terna para el gobierno de Coahuila; aunque desde 1793 buscó que se le diera el gobierno militar y político de la Provincia de Sonora. ${ }^{26}$

Vale la pena hacer una revisión, aunque sea somera, de diversos episodios del desempeño de Diego de Borica, porque a través de sus distintas asignaciones iba aflorando un conjunto de criterios técnicos que explican sus dotes de organizador del territorio. La primera noticia que tenemos, se refiere a una orden que le dio el gobernador De Mendinueta, para que con 250 hombres explorara las sierras de la Magdalena y Ladrones, interviniendo así en la campaña general contra indios de 1776. Lo mismo debió acontecer con motivo de exploraciones en el área de Tucson y el río Gila, donde sobresale que probablemente estuvo en Bavispe, porque dirigió un escuadrón de ópatas; esta expedición arrojó 68 muertos, 17 prisioneros apaches, 2 cautivos y 168 bestias rescatadas, además de un cuantioso botín de pieles de cíbolo y gamuza (Navarro, 1964, p. 249).

En otro ejemplo, en 1778, cuando se discutió el traslado de una compañía presidial al paraje de Chavarría -con la implicación del establecimiento de la nueva villa de San Juan Nepomuceno-, De Borica estuvo al tanto de las decisiones del capitán Nicolás Gil, quien recibió unas completas Instrucciones de De Croix para dicho establecimiento. Interesa, sobre todo, el esquema de organización de la obra de construcción, pues en primera instancia todos los pobladores -civiles y militares - deberían colaborar, comenzando con diez casas para soldados, diez para vecinos españoles y cinco para indios. Solamente después de haber concluido las casas, se procedería con las obras de la iglesia, casas reales, del padre

25 Relación de méritos de Diego de Borica, Madrid, 1795, AGi, Guadalajara 500.

26 Memorial del teniente coronel don Diego de Borica, Chihuahua, 1793, AGn, Provincias Internas, Vol. 60, Exp. 1. 
capellán, oficiales alternos, sargentos, cárcel, cuerpo de guardia y alhóndiga. Se sabe que los capitanes de presidios contaban con una asignación de dinero para afrontar gastos; sin embargo, en este caso Nicolás Gil ofreció levantar, a su costa, las casas reales, y poner mulas y bueyes para el movimiento de madera, y aclaró: “... el trabajo material de la fábrica debe hacerse por los vecinos y soldados sin percibir otro jornal ni gratificación que los socorros de dos reales diarios". Los pobladores, se aclaró, deberían ser aquellos que antes estaban en asentamiento disperso. ${ }^{27}$ Pero los vecinos no quisieron aceptar este trato, de modo que el capitán tuvo que emplear sus asignaciones y contratar indios de las misiones de Carichí, Yemáchi, Coyáchi, Papigóchi, Matachi y Temósachi. ${ }^{28}$

En una carta que preparó Teodoro de Croix, para el conde de Gálvez en el mismo año, se advierte que De Borica estaba comisionado para la revista de inspección de los presidios. También queda claro que De Croix, De Borica y el ingeniero Agustín Mascaró debieron haber conferenciado juntos en algún momento en Janos, con motivo de la red de nuevas poblaciones que ideó el comandante general con miras a facilitar la comunicación con Sonora. ${ }^{29}$ Durante este tiempo el capitán Juan Bautista Perú estuvo encargado de llevar adelante dicho plan, desde el punto de vista de los trazos y las obras de construcción; por eso De Borica informó sobre el avance de las obras. ${ }^{30}$ Lo mismo sucedió con el traslado del presidio del Carrizal, el mismo año, pues escribió una Instrucción para el comandante, donde, entre otras cosas, indicó que no se permitiera que se fabricaran casas afuera de la plaza, y que a quienes ya vivían fuera se les obligara a reunirse (artículo

27 Instrucción que el capitán don Nicolás Gil va a observar en la traslación del presidio a su cargo al paraje que llaman de Chavarría, Chihuahua, 1778, AGI, Guadalajara 270; e Informe de Nicolás Gil, presidio del Carrizal, 1778, ibidem.

28 Ibidem.

29 El comandante general de Provincias Internas de Nueva España dice sus providencias para la erección de una nueva villa en el presidio de Janos, Chihuahua, 1778, ibidem.

30 Papel de puntos que hace presentes el capitán de caballería don Diego de Borica al señor Teodoro de Croix, Janos, 1778, ibidem. 
8. ${ }^{\circ}$. Las obras del templo, también informó De Borica, estaban en proceso de terminarse, y del mismo modo elaboró un censo. ${ }^{31}$

También en 1778 Teodoro de Croix elaboró una nota titulada Fomento del Pueblo del Paso, y firmada desde Chihuahua. En esta se hablaba de que el gobemador, Juan Bautista de Anza, debía proponer los medios para remediar la dispersión de casas del vecindario, para que se formara "una población unida, arreglada y respetable". Se aconsejó que había que revisar los títulos de merced de tierra y ver si los dueños habían o no cumplido con sus obligaciones. ${ }^{32}$ De forma paralela, De Borica vigiló que las cosas se hicieran conforme a las leyes, pues el mismo año no dejó de comentar que en Paso del Norte los españoles se habían posesionado de los mejores sitios y solares, dejando a los indios - antiguos poseedores - que paulatinamente se fueran asentando en las orillas de la población. ${ }^{33}$ Pero - hay que recalcar que- todo esto sucedió con motivo de la organización de milicias en este punto.

Para el año de 1781 De Borica firmó un padrón de habitantes de San Elizario, ${ }^{34}$ y preparó un informe de revista de la compañía del presidio de Janos. En este último punto estaba también ocupado de revisar la obra del presidio, donde viendo que un lienzo del baluarte se había caído, recomendó que se organizaran faenas entre la tropa, vecinos y "muchachos" para que lo levantaran en un plazo de quince días. Respecto a las caballerizas informaba que se habían fabricado alrededor de diez mil adobes, se había cortado madera, pero la poca "tropa franca" y la escasez de bueyes no habían permitido que se concluyera el trabajo. Sobre las puertas del presidio indicó que solamente una de las cuatro debería quedar habilitada, cerrándose las otras tres. ${ }^{35} \mathrm{El}$ mismo año, en Carrizal, señaló que no existían suficientes pobladores para levantar la co-

31 Instrucción que deberá observar el comandante del presidio del Carrizal, que hoy es, y en adelante fuere, para el mejor gobierno del vecindario agregado a él, Carrizal, 1778, ibidem.

32 Fomento del Pueblo del Paso, Chihuahua, 1778, AGi, Guadalajara 267.

33 Informe sobre formación de milicias en Paso del Norte, Chihuahua, 1778, AGi, Guadalajara 267.

34 Noticia del estado de los vecinos de San Elizario, San Elizario, 1781, ibidem.

35 Documentos de la revista pasada a la compañía del presidio de Janos, Arizpe, 1781, AGI, Guadalajara 271. 
secha. ${ }^{36}$ Y levantó un censo y supervisó las obras de construcción, donde indicaba que la iglesia estaba en proceso de conclusión y que a las caballerizas solamente les faltaba techumbre, y escribía con cierta satisfacción que "la plaza de los vecinos se está acabando de cerrar con nuevas casas". ${ }^{37}$

Es difícil imaginar la opinión de De Croix sobre el papel y desempeño de Diego de Borica, pero una cosa cierta es que el mismo año de 1781 lo recomendaba como parte de una terna para que se hiciera cargo del gobierno de Coahuila. La nota destacó su puesto como capitán del presidio de San Elizario, la inspección de compañías presidiales y, sobre todo, el cuidado de las tierras para cultivo y sus empeños en "la protección" de poblaciones. ${ }^{38}$

Ahora bien, vale la pena detenerse a revisar las "obras de reunión” mencionadas en su relación de méritos. El título completo del documento es Diario de lo que va practicando el capitán Diego de Borica para la consecución de la reunión de indios y vecindario de la jurisdicción de los pueblos del Paso del Río del Norte, y es probable que si no ha sido citado por historiadores es debido a dos razones: primero, porque se encuentra separado en dos partes, y en distintas cajas con el orden volteado, es decir, primero se encuentra la segunda parte y en otra caja está la primera, y probablemente no se advirtió su unidad cuando se microfilmaron varios expedientes del archivo; y segunda, porque tal vez no hubo interés en los planes o proyectos que parecieron no haberse llevado a cabo. ${ }^{39}$

El diario explica las operaciones efectuadas entre el 5 y 29 de abril, y primeros días de mayo, del año de 1782, en Paso del Norte, el Real, Senecú, Isleta y Socorro. Aunque parece que se refiere solamente a la "reunión de indios y vecindario", también contiene un reconocimiento de posesiones, terrenos y referencias a juntas

36 Revista de inspección del presidio del Carrizal, Paso del Norte, 1781, ibidem.

37 Estado del vecindario del Carrizal, Carrizal, 1781, AGi, Guadalajara 272.

38 Informe para Coahuila, Arizpe, 1781, AGi, Guadalajara 302.

39 En adelante se citan en orden las dos partes del diario. Véase: Diario de lo que va practicando el capitán Diego de Borica para la consecución de la reunión de indios y vecindario de la jurisdicción de los pueblos del Paso del Río del Norte, Paso del Norte, 1782, AHCJ, FC, caja 15, Exp. 1; e idem, AHCJ, FC, caja 14, Exp. 2. También hubo que reordenar algunos de los 31 folios que constituyen el diario, que fueron escritos en distintos momentos, a decir de los cambios en el tipo de tinta. 
de vecinos e indios que debieron practicarse para el propósito. De la correspondencia que antecede al diario, se deduce que Diego de Borica estaba cumpliendo las ya mencionadas órdenes del comandante general Teodoro de Croix; y enviaba el resultado al teniente gobernador Eugenio Fernández. Para el momento existían cinco pueblos habitados, que estaban involucrados en el plan. De Borica señaló en los prolegómenos que era necesario obligar a indios y vecinos a vivir en "plazas de corto recinto", e intentar que se alejaran - aunque fuera temporalmente- de sus casas, huertas, corrales, chiqueros, hortalizas y tierras de panllevar. Los cinco pueblos eran El Paso, El Real, Senecú, Isleta y Socorro, y parece que, al momento de la redacción, ya se habían celebrado reuniones para la organización requerida de trabajos. ${ }^{40}$

Figura 3. Primer folio del diario de Diego de Borica de 1782

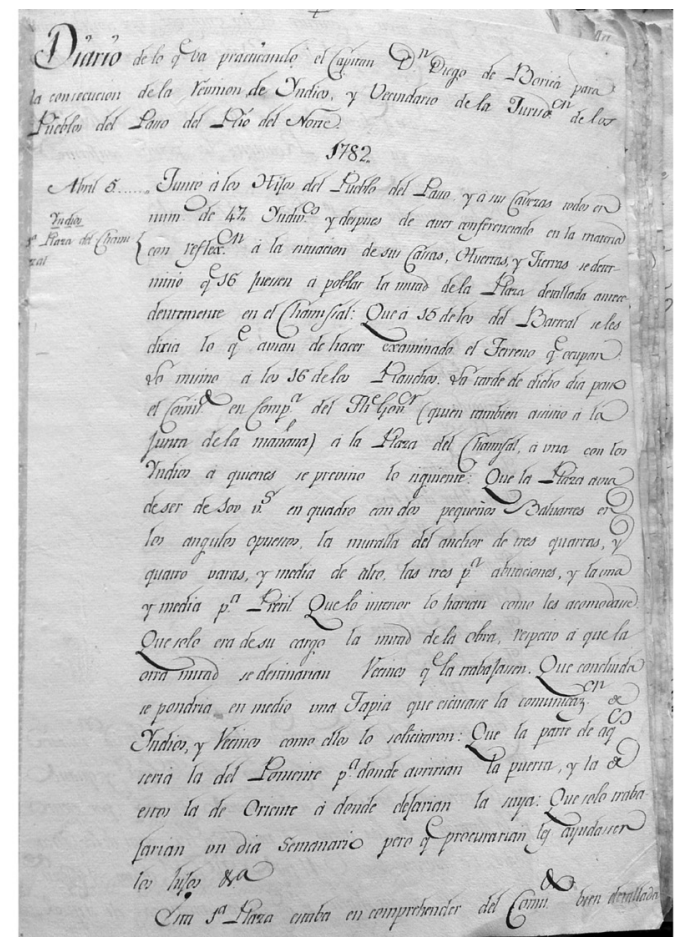

40 Idem. 
Fuente: Diario de lo que va practicando el capitán Diego de Borica para la consecución de la reunión de indios y vecindario de la jurisdicción de los pueblos del Paso del Río del Norte, Paso del Norte, 1782, AHCJ, FC, caja 15, Exp. 1; e idem, AHCJ, FC, caja 14, Exp. 2.

En el primer caso, El Paso - que era la zona más poblada-, se recomendó que se unieran las posesiones a través de una tapia circundante, y se formaran calles de doce varas de ancho y callejones, "de manera que se verifica unión, y un laberinto tal que solo los paseños prácticos en él podrán entenderlo”. Es interesante considerar que la red irregular de caminos se mantendría sin cambios e, incluso, se juzgó en términos positivos y de acuerdo con las ideas de los vecinos que antes se habían negado a abandonar sus suertes o huertas. Un objetivo era cercar toda la parte poblada, para que no quedase ninguna casa afuera. Un resultado de esta operación, aseguraba De Borica, sería el aumento del valor de los terrenos, además de alejar los daños que frecuentemente los ganados mayores y menores provocaban cuando salían a pastar y regresaban. Las calles que quedarían libres al tránsito serían la del Pueblo del Real y la del capitán Elías. En El Real también se indicó que los indios deberían establecerse en una plaza inmediata a la iglesia, y los vecinos formarían tres cercas en división. En Senecú se habló con los indios para que también formaran plaza junto a la iglesia, y los vecinos cercaran en tres divisiones, como en El Paso. En Isleta se propuso lo mismo, aunque en cuatro divisiones. Para el caso de Socorro, se determinó que, además de la plaza, era necesario formar dos cercas: una junto a la iglesia, para los indios y sesenta vecinos, y otra a una distancia de dos tiros de escopeta para treinta vecinos. Quedaba pendiente resolver si se haría algo o no en el rancho de Tiburcios. Considerando que el diario se hizo sobre reuniones y acuerdos del mes de abril, es interesante advertir que para el mes de mayo informaba De Borica que algunas obras estaban en marcha, vigilándolas el teniente gobernador -Germán Durán-y Antonio Vargas, quien era sargento de San Elizario. ${ }^{41}$

41 Idem. 
Ahora bien, una descripción pormenorizada de lo que se discutió y ordenó cada día permite observar todos los anteriores aspectos del poblamiento en una escala más concreta. Entre el 5 y 23 de abril, se atendió lo relativo a El Paso, que contempló los siguientes partidos o barrios: El Chamizal, El Barreal, Los Ranchos, Camino Real, Las Lomas, Plaza de los Indios, centro de El Paso, área de Lorenzo, El Largo, Los Álamos, La Playa y Las Calaveras. A continuación, el día 28 se visitó Senecú, el 29 El Real, el día 6 de mayo se recorrió Socorro y el 7 del mismo mes se visitó Isleta. ${ }^{42}$ En cada punto se tomaron varias decisiones más detalladas.

Respecto al área central de El Paso, y empezando con la Primera Plaza de El Chamizal, se celebró el 5 de abril una reunión con cuarenta y siete personas, y después de reflexionar sobre la situación de casas, huertas y tierras, se determinó que solamente dieciséis se movieran a la plaza. En El Barreal se hizo lo mismo con quince, y con dieciséis en Los Ranchos también. En el caso de la Plaza de El Chamizal, con los indios, se dispuso que la plaza debía ser de 100 varas en cuadro con 2 pequeños baluartes en ángulos opuestos, y la "muralla" de anchura de $3 / 4$ de vara, y 4 1/2 de alto -3 para la altura de las habitaciones y $1 \frac{1}{2}$ para el pretil. ${ }^{43}$ En el interior podrían construir como quisieran, y solamente habría que dividir dos partes para separar vecinos e indios; los accesos deberían abrirse hacia el poniente y hacia el oriente, y solo se trabajaría un día a la semana; para los quince indios que se asignaron figuraba como encargado o mandón Juan Nicolás. ${ }^{44}$

El día 9 el teniente gobernador se reunió en Los Ranchos con los indios, quienes ya tenían tierra de panllevar, y acordaron hacer la plaza de cincuenta varas en cuadro con los mismos detalles de la referida atrás. La plaza debería ubicarse en algún extremo, porque se mencionó que esta protegería el interior de la población de El Paso (tal vez por su cercanía). Se agregó al vecino Asensio Suazo, y se asignaron quince indios bajo la vigilancia de Juan Candelario. ${ }^{45}$

\footnotetext{
42 Idem.

43 Si bien es obvia la referencia a los cuartos que cierran la plaza, el mismo De Borica empleó la palabra "muralla".

44 Idem.

45 Idem.
} 
El día 11 se pasó a El Barreal, y después de identificar las posesiones de cada indio se dispuso formar una cerca que comenzaría en la casa del gobernador, la cual seguiría rodeando las huertas y remataría en el puente de la Morunda. En este caso fueron dos vecinos, mezclados con los indios —quizá Josef Manuel Téllez y Pedro Padilla-, quienes tomaron la decisión de formar una cerca para sus dos posesiones; otros vecinos quedaban a un lado del Camino de Chihuahua, y otros más tuvieron que cercar por ellos mismos (Antonio Rojas, Gerónimo Ledesma, Juan Antonio Salayandía, Rosa Velarde y Francisco Castillo). Estas cercas o bardas de adobes, señaló De Borica, tenían la reputación de ser "tapias duraderas". ${ }^{46}$

El día 13 de abril el teniente gobernador y el alcalde de aguas - Josef Manuel Téllez- pasaron a otras cuatro o cinco casas con sus huertas, del mismo Barreal. Aquí también debió de haberse concedido mantener las formas irregulares de los terrenos de Horacio Durán, Juan Josef Fernández, Antonio Madrid, Petrona Trujillo, Josef Provencio y José Fernández, en un grupo, y también los de Vicente Martínez, Antonio Contreras, Antonio Provencio y Juan Francisco Lucero en el otro. La anchura de caminos se estableció en doce varas, porque se indicó que esto favorecía -en el caso de la entrada de indios enemigos- que la huida se diera con dificultad, “... pues no es regular que estando huertas y tierras encadenadas de tapias se metan en un laberinto que les imposibilite la retirada". Los días 14 y 15 se continuó la inspección de casas y huertas de otros vecinos (Cayetano García, Juan Francisco Alderete, Manuel Provencio y Luciana Alderete), también de El Barreal, y por estar en colindancia con el Camino Real. Cada dueño debería construir su propia cerca, y es probable que esta área se haya extendido hacia el sur. ${ }^{47}$

El mismo día 15 se pasó al lugar donde debería construirse la Tercera Plaza de Las Lomas, de setenta varas en cuadro, en la casa de uno de los vecinos; el encargado de los trabajos sería Santiago Gómez. Otro vecino quedaba en colindancia con la Se-

46 Idem.

47 Idem. 
gunda Plaza de los Indios (Los Ranchos), y se consideró viable aprovechar una parte de esta para construir la nueva. El día 16 continuó hablándose con vecinos en el Camino Real, y se consideró suficiente levantar cercas. En el centro de El Paso solamente se comentó que había que buscar que los caminos fueran de doce varas de anchura y los callejones, de seis varas, quedando como encargado Germán Durán. El día 17 se comentó lo relativo a la casa de Lorenzo el Largo —encargado de la obra-, para formar una Cuarta Plaza; se ubicaba a un lado de Las Lomas, y protegía el interior de la población, es decir, estaría en un extremo “... que hace como cabeza de calle” entre la acequia Madre y la de El Chamizal, de modo que los vecinos también tendrían que levantar tapias en el camino, las huertas y los callejones. ${ }^{48}$

El día 18 se visitó El Chamizal, que, al parecer, ya había recibido una instrucción para concentrarse - dada antes por el capitán Nicolás Soler - y ya estaban construyendo pero mal, y entonces se les instruyó que hicieran una "muralla" de 3 1/2 varas de altura, 3/4 de ancho y cimientos "que abrazase todo el Chamizal, casas y huertas”, empezando por la casa de Balizán y terminando en la Loma de Arena que estaba inmediata a la acequia Madre. ${ }^{49}$ Es interesante notar que los indios que estaban asignados para la Primera Plaza abandonaron su obra, y vinieron a trabajar esta nueva. ${ }^{50}$

El 19 de abril se procedió con la inspección del "barrio" de Los Álamos, donde también se había recibido - por Nicolás Soler-, desde tiempo atrás, la instrucción de reunir y cercar. Parece que no lo habían hecho, por lo cual se volvió a dar la orden de hacerlo, empezando en donde se ubicaban los chamizaleños y terminando en el molino de la casa de la viuda Marta. En este caso, se tomó una decisión constructiva interesante, pues como eran pocos los vecinos se consideró mejor construir la barda de cajones y adobes, con sus caballetes, y donde el cálculo de la longitud total arrojó una distancia de tres mil quinientas varas. A partir de la casa de Marta, se levantarían paredes a cada lado del Camino Real. La

48 Idem.

49 Es evidente que aquí la "muralla" se refiere a la cerca.

50 Idem. 
inspección continuó el día 21 en El Chamizal, disponiendo que los vecinos españoles trabajarían dos días a la semana y los indios un día (todos con ayuda de sus hijos). ${ }^{51}$

El día 22 continuaron dándose instrucciones para levantar paredes en torno al Camino Real; se consideró que la obra, de estar bien hecha, podría durar hasta cincuenta años más o menos, y que tardaría en construirse hasta seis años. El día 23 se visitó Las Calaveras, y se mandó cercar casas, huertas y tierras, empezando desde la acequia Madre, enfrente de la casa de Elías y hasta la de Juan Domingo García, que estaba próxima al pueblo de indios. Para el día 24 se formó una lista muy larga de gente que debería trabajar en esta obra. ${ }^{52}$ 
Figura 4. Descripción hipotética de proporciones entre plazas y dimensión de los templos
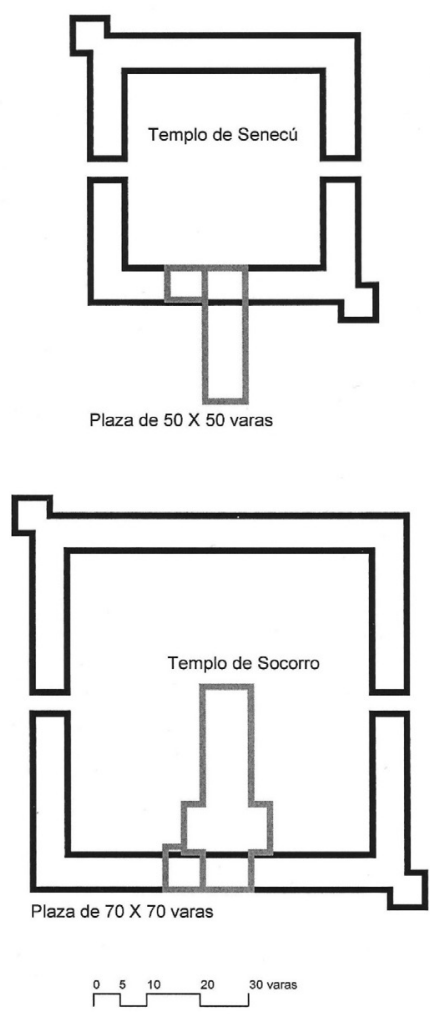
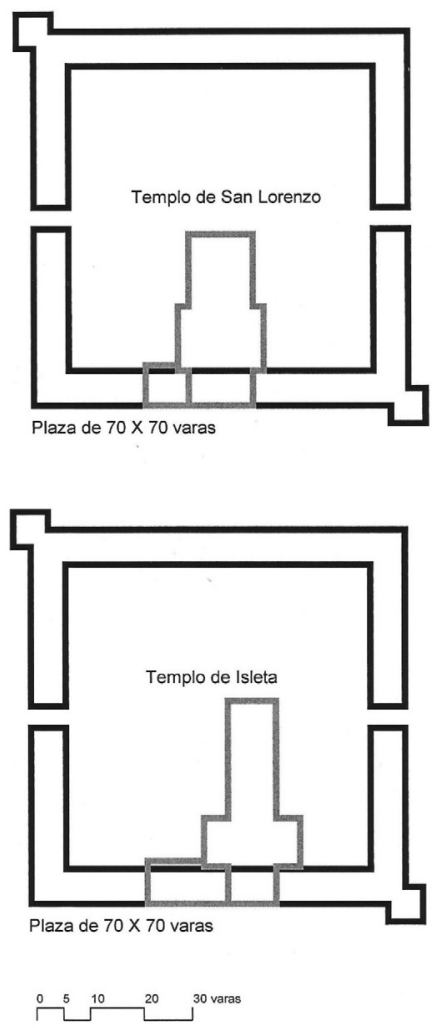

Fuente: elaborado por el autor con base en el diario de Diego de Borica y datos de la visita a Paso del Norte de Pedro Tamarón, hacia 1759, que contiene las dimensiones de los templos. ${ }^{53}$ La mayoría de las propuestas eran pequeñas en dimensión, y las "divisiones cercadas" se refieren a porciones de huertas externas. Las naves de los templos pudieron ubicarse hacia fuera, pero con el acceso hacia el interior, aunque también en el sentido largo de cualquier crujía de la plaza (que contiene cuartos en todos los casos). Los baluartes los indicó el mismo De Borica.

Las indicaciones de obra y tareas de construcción continuaron hasta el día 28 en Senecú. Con indios y vecinos se acordó que

53 Libro que se destina para registrar las Providencias de Visita que hace en su Obispado el Ilmo. Sr. Pedro Tamarón de este Obispado de Durango, 20 de octubre de 1759, ahad, caja 6, sin número de expediente. 
los primeros formaran plaza junto a la iglesia, y los segundos, más dispersos, deberían levantar cercas en tres divisiones como en El Paso. El día 29 se pasó a El Real, donde también se indicó que había que formar plaza junto a la iglesia —en tres divisiones- y se dispuso que el encargado del trabajo de los indios sería Lorenzo Amparán. El día 6 de mayo, en Socorro, se dispusieron dos divisiones, o cercos, junto a la iglesia; uno comprendería a los indios y a cerca de treinta vecinos, y el otro - a distancia de dos tiros de escopeta - a treinta vecinos. Solo hasta el 7 de mayo, se visitó el pueblo de la Isleta, donde se acordó entre todos construir casas de adobe en la plaza que se formaría junto a la iglesia, para lugar de los indios, y también cercar casas y huertas en cuatro divisiones para los vecinos. ${ }^{54}$

En cada pueblo, partido y barrio se formaron listas para designar encargados y a la gente que colaboraría en las obras, que muestran que convivían indios y vecinos, y que el mando de cada sección, en cierto modo, sería tomado por las personas que podrían considerarse como principales. Por lo que se ha visto, parece que a los indios tendería a congregárseles y a los vecinos se les aplicarían cercas, dado el tamaño y la dispersión de sus posesiones.

El siguiente cuadro presenta un resumen con todo el contenido del diario, que expresa el sitio donde se planteó la reforma, los datos disponibles sobre obras y sus medidas, cuando las hubo, y, por último, el número de personas enlistadas para colaborar con los trabajos.

54 Idem. 
Cuadro 1. Resumen del contenido del diario de Diego de Borica

Paso del Norte

\begin{tabular}{|l|l|l|}
\hline Primera Plaza del Chamizal & $100 \times 100$ varas con dos baluartes & 16 indios y un vecino \\
\hline $\begin{array}{l}\text { Segunda Plaza de Indios (Los } \\
\text { Ranchos) }\end{array}$ & $50 \times 50$ varas con dos baluartes & 16 indios \\
\hline El Barreal & $\begin{array}{l}\text { Varias secciones de cercas de perímetro } \\
\text { irregular }\end{array}$ & 16 indios \\
\hline Tercera Plaza de las Lomas & $\begin{array}{l}70 \times 70 \text { varas con dos baluartes; } y \text { cercas en } \\
\text { camino real }\end{array}$ & 8 vecinos \\
\hline Centro del Paso & Sin especificaciones & 44 vecinos \\
\hline Cuarta Plaza de Lorenzo el largo & $\begin{array}{l}\text { Sin medidas; } y \text { cercas en el camino, huertas y } \\
\text { callejones }\end{array}$ & 42 vecinos \\
\hline Plaza del Chamizal & $\begin{array}{l}\text { Sin medidas; } y \text { cercas en el camino, huertas y } \\
\text { callejones }\end{array}$ & 15 indios y 109 vecinos \\
\hline Plaza de la Playa y los Álamos & $\begin{array}{l}3,500 \text { varas de perímetro; } y \text { cercas sobre el } \\
\text { camino, y empleo de cajones y adobes }\end{array}$ & 86 vecinos \\
\hline Las Calaveras & $\begin{array}{l}\text { Sin medidas; } y \text { cercas en el camino, huertasy y } \\
\text { callejones }\end{array}$ & 62 vecinos \\
\hline & & $\mathbf{6 3}$ indios + 352 vecinos \\
\hline
\end{tabular}

Senecú

\begin{tabular}{|l|l|l|}
\hline Senecú & $\begin{array}{l}\text { Plaza junto a la iglesia y tres divisiones } \\
\text { cercadas }\end{array}$ & 79 indiosy (?) vecinos \\
\hline
\end{tabular}

El Real (San Lorenzo)

\begin{tabular}{|l|l|l|}
\hline El Real & $\begin{array}{l}\text { Plaza junto a la iglesia y tres divisiones } \\
\text { cercadas }\end{array}$ & 13 indios y 22 vecinos \\
\hline
\end{tabular}

Socorro

\begin{tabular}{|l|l|l|}
\hline Socorro & Junto a la iglesia, dos divisiones cercadas & 122 indios y 60 vecinos \\
\hline
\end{tabular}
\begin{tabular}{|l|l|l|}
\hline Isleta & TOTAL 182 \\
\hline Isleta & $\begin{array}{l}\text { Casas de adobe en la plaza, junto a la iglesia, y } \\
\text { cercas sobre casas y huertas en cuatro } \\
\text { divisiones }\end{array}$ & 50 indios y 28 vecinos \\
\hline
\end{tabular}

TOTAL 78

Fuente: Diario de lo que va practicando el capitán Diego de Borica para la consecución de la reunión de indios y vecindario de la jurisdicción de los pueblos del Paso del Río del Norte, Paso del Norte 1782, AHCJ, FC, caja 15, Exp. 1; e idem, AHCJ, FC, caja 14, Exp. 2. Es interesante advertir que se involucró en estas operaciones a 789 personas, que representaron aproximadamente la quinta parte de toda la población del área. Si bien, en Senecú, el diario indicó a varios vecinos, no se mencionó su número.

Hay que tomar en cuenta que en esta misma década, Diego de Borica había dispuesto una serie de medidas para las obras de San Elizario, entre las cuales estaba el detalle de un adobe específico para construcción, con medidas de 2/3 de varas de largo, 
1/3 de vara de ancho y 5 dedos de alto; a esta pieza se le conoció como "adobe de 5 " ${ }^{55}$ También puede inferirse que el propósito del diario no era nada sencillo de cumplir, pues, entre otras cosas, cada barda requería mucho tiempo para levantarse. Al menos esta era la recomendación del ingeniero Gerónimo de la Rocha:

Todas las obras de adobes son de por sí falsas por no componerse más que de tierra, y por consiguiente la mayor solidez consiste en que se tenga especial cuidado en la trabazón o enlace de las paredes procurando no cargarlas de golpe sin dar tiempo a que se vayan secando $[\ldots]^{56}$

\section{A MANERA DE CONCLUSIÓN}

Durante el siglo xviI varios gobernadores de Nuevo México, y el comandante general de Provincias Internas, discutieron la necesidad de combatir la dispersión de los asentamientos y exploraron los mecanismos para obligar a los pobladores a vivir reunidos y a construir sus casas en plazas. De la mano de la formación de milicias, las tareas de construcción debieron ser lentas y tendieron a privilegiar la ubicación de casas en las huertas o suertes de tierra, y no favorecieron -en cambio- la conformación del recinto compacto. Los repartos de tierra a los indios —en El Paso- no sugieren que se hubiera buscado la compactación o formación de plazas, ni siquiera en el caso de Tomás Vélez, quien -al contrario- sí tuvo esta consideración para varios establecimientos de Nuevo México (Nostrand, 1992, pp. 72, 80-95; Carlson, 1990, pp. 27-31; Patrick 1976, pp. 10-13). Más bien, la ubicación de huertas y labores respondió al trazo de las acequias que aseguraban la pendiente de regadío suficiente para ciertas extensiones. Y tampoco en el caso de Carrizal, se consiguió el ansiado propósito de la compactación. Hoy parece necesario incorporar a la historiografía

55 Obras en el presidio de San Elizario, Paso del Norte, 1789, AHCJ, FC, caja 15, Exp. 1.

56 Instrucción para el encargado de la dirección de la nueva fábrica de un presidio, Arizpe, 1781, SANM, MF454, Roll 11. 
experiencias como la de Diego de Borica, quien emprendió su proyecto de "reunión", cosa que debió valerle algún reconocimiento.

A final de cuentas, Diego de Borica defendió frente a Teodoro de Croix la consideración de balancear plazas con huertas cercadas, indicando que esta era la mejor manera de conseguir las ideas del rey, pues "de reducirlos a plazas", a indios y vecinos les resultarían graves daños. El año siguiente a la publicación del diario, De Croix confirmó estos "medios suaves" que debían seguirse empleando para continuar y concluir las obras de reunión. ${ }^{57}$ Los cambios de posición de varios pueblos, debido a crecientes del río Grande, volvieron impracticable la construcción de plazas.

También los "Valles" en Nuevo León y Nueva Vizcaya, en otro ejemplo, durante el siglo XVII, se constituían como grupos de granjas de mediano tamaño, esparcidos en territorios no pequeños y contaban cada uno con su alcalde. Es decir, en términos políticos manifestaban una posición dentro de la categoría de lo urbano; habían sido resultado de un proceso paulatino de fragmentación de las primeras grandes posesiones para ganaderos, y todavía hasta mediados del siglo XIX, al menos en Nuevo León, los gobernadores intentaban atacar tal dispersión buscando formar poblaciones compactas - en torno a plazas y calles-, pero sin conseguirlo del todo.

Todavía a inicios del siglo xx, en la ahora llamada Ciudad Juárez, volvieron a discutirse los problemas de la dispersión, e igualmente se exploraron opciones de planificación. Pero esto ya es otra historia.

\section{REFERENCIAS}

Archivos

Archivo General de Indias (AGI)

Archivo General de la Nación (AGN)

Archivo Histórico del Arzobispado de Durango (AHAD)

Archivo Histórico de Ciudad Juárez (AHCJ). Fondo Colonial (FC)

Mapoteca Manuel Orozco y Berra (ммоув)

57 Obras en el presidio de San Elizario, Paso del Norte, 1789, AHCJ, FC, Caja 15, Exp. 1. 
Tres episodios de asentamiento y un diario de obras en Paso del Norte...

Spanish Archives of New Mexico (SANM). Microfilm Collection UTEP Spanish Archives of New Mexico (SANM). State Archives of New Mexico

\section{BIBLIOGRAFÍA}

Arnal, L. (1998). El presidio en México en el siglo XVI. México: Universidad Nacional Autónoma de México.

---- (2017). Los presidios en el norte de África y en la Nueva España. En M. F. Ríos Saloma (Ed.), El mundo de los conquistadores (pp. 197-226). México: Universidad Nacional Autónoma de México.

Carlson, A. W. (1990). The Spanish-American Homeland. Baltimore, \& London: The Johns Hopkins University Press.

Chávez, A. B. (1970). Historia de Ciudad Juárez. Ciudad Juárez: s.p.i.

De Palo, W. (1973). The Establishment of the Nueva Vizcaya Militia during the Administration of Teodoro de Croix, 1776-1783. New Mexico Historical Review, 48(3), 223-249.

De Rivera, P. (1945). Diario y derrotero de lo caminado, visto y observado en el discurso de la visita general de Presidios, situados en las Provincias Internas de Nueva España. México: s.p.i. Ebright, M. (2014). Advocates for the Oppressed. Albuquerque: University of New Mexico Press.

González, M. (2012). La conformación interna y la articulación territorial de la región de El Paso del Norte en la época colonial, 1659-1824. En V. Orozco (Coord.), Ciudad Juárez, la nombradía varia (pp. 43-65). México: Grupo Editorial Milenio.

Hackett, C. W. (1926). Historical Documents relating to New Mexico, Nueva Vizcaya, and Approaches Thereto, to 1773, iII. Washington: Carnegie Institution for Science.

Hendricks, R., \& Timmons, W. H. (1998). San Elizario: Spanish Presidio to Texas County Seat. El Paso: The University of Texas at El Paso.

Herrera, C. R. (2004). Juan Bautista de Anza and the SocialMilitarization of Bourbon El Paso: 1778-1788. Journal of the Southwest, 46(3), Autumn, 501-528. 
Kelley, W. D. (1955). Settlement of the Middle Rio Grande Valley. Journal of Geography, 54(8), 387-399.

Meyer, M. C. (1984). El agua en el Suroeste hispánico. Una historia social y legal, 1550-1850. México: Centro de Investigaciones y Estudios Superiores en Antropología Social/Instituto Mexicano de Tecnología del Agua.

Moorhead, M. L. (1975). The Presidio. Bastion of the Spanish Borderlands. Norman, Oklahoma: University of Oklahoma Press.

Navarro, L. (1964). Don José de Gálvez y la Comandancia General de las Provincias Internas del norte de Nueva España. Sevilla: Consejo Superior de Investigaciones Científicas.

Nostrand, R. L. (1992). The Hispano Homeland. Norman, Oklahoma \& London: University of Oklahoma Press.

Ortelli, S. (2007). Trama de una guerra conveniente. Nueva Vizcaya y la sombra de los apaches (1748-1790). México: El Colegio de México.

Patrick, E. N. (1976). Land Grants during the Administration of Spanish Colonial Governor Pedro Fermín de Mendinueta. New Mexico Historial Review, 51(1), 5-18.

Ramiro, D. (2013). Arquitectura y urbanismo de los pueblos de misión y colonias tlaxcaltecas: Coahuila y el Nuevo Reino de León en el siglo xvIII. Tesis de doctorado. México: Universidad Nacional Autónoma de México.

Santiago, G. (2013). Políticas federales e intervención empresarial en la configuración urbana de Ciudad Juárez, 1940-1992. Ciudad Juárez: Universidad Autónoma de Ciudad Juárez/E] Colegio de Michoacán.

Simmons, M. (1976). Patrones de asentamiento y planes de las aldeas en Nuevo México en la época colonial. En D. J. Weber (Coord.), El México perdido: ensayos escogidos sobre el antiguo norte de México (1540-1821) (pp. 68-88). México: SEPSetentas.

Thomas, A. B. (1931). Governor Mendinueta's Proposal for the Defense of New Mexico, 1772-1778. New Mexico Historical Review, 6(1), 21-39. 
---- (1941). Teodoro de Croix and the Northern Frontier of New Spain, 1776-1783. Norman, Oklahoma: University of Oklahoma Press.

Timmons, W. H. (1990). El Paso: A Borderlands History. El Paso: The University of Texas at El Paso.

Torales, J. M. C. (2001). Ilustrados en la Nueva España. México: Universidad Iberoamericana.

Urquidi, M. (1992). Una familia de Chihuahua en el siglo xviI y sus lazos con ciudad, campo y frontera. La ciudad y el campo en la historia de México (T. II, pp. 665-672). México: Universidad Nacional Autónoma de México.

Vázquez, G. (2013). El proyecto de poblamiento de Teodoro de Croix en la Nueva Vizcaya. En L. Arnal, \& D. Ramiro (Eds.), Arquitectura y urbanismo del Septentrión Novohispano (Vol. Iv, pp. 133-148). México: Universidad Nacional Autónoma de México.

Villagutierre, J. [1601]. Historia de la conquista, pérdida y restauración del reino y provincias de la Nueva México en la América Septentrional. Manuscrito: Biblioteca Nacional de España.

Weber, D. J. (2000). La frontera española en América del Norte. México: Fondo de Cultura Económica.

Wilson, C. (2011). Center Place, Plaza Square. En C. Wilson, \& S. Polyzoides (Eds.), The Plazas of New Mexico (pp. 9-51). San Antonio: Trinity University Press. 